\title{
Perbedaan Pola Menyusui Bulan Pertama Ibu Melahirkan Seksio Sesarea dibandingkan Melahirkan Normal di Rumah Sakit Sayang Bayi
}

\author{
Winda Nurmayani ${ }^{1}$, Madarina Julia ${ }^{2}$, Shinta Prawitasari ${ }^{3}$, \\ ${ }^{1}$ Stikes Yarsi Mataram \\ ${ }^{2}$ Departemen IImu Kesehatan Anak, Fakultas Kedokteran, Kesehatan Masyarakat dan Keperawatan, UGM \\ ${ }^{3}$ Departemen Obstetri dan Ginekologi, Fakultas Kedokteran, Kesehatan Masyarakat dan Keperawatan, UGM \\ Korespondensi: windayarsi@gmail.com
}

Submisi: 28 November 2018; Revisi: 20 Desember 2018; Penerimaan: 24 Desember 2018

\begin{abstract}
Background: Exclusive breastfeeding should be provided until 6 months of age, but the fact proves that the pattern of breastfeeding has decreased. The pattern of the first month lactation is a critical period for the survival of the subsequent breastfeeding, so it is necessary to make efforts to maintain the duration of breastfeeding because the success of the first month breastfeeding will increase mothers' confidence to continue breastfeeding. Objective: To determine differences in the pattern of the first month breastfeeding in mothers who gave birth by cesarean section compared to those by vaginal delivery in Rumah Sakit Sayang Bayi (Baby Friendly Hospital)

Method: Type of research is comparative observational with a prospective cohort design using a quantitative approach. The research was conducted in Baby Friendly Hospital of RSUD (General Hospital) Mataram City. Total sample 120 consisted of 60 mothers giving birth the caesarean section and 60 mothers vaginal delivery. The independent variable of giving birth by Cesarean Section and vaginal delivery, dependent variable pattern the first month of breastfeeding and external variables age, parity, employment, the incidence of antepartum and postpartum. The sampling technique using consecutive sampling. Analysis of the data used is univaribel, bivariate using Chi-square and Fisher's exact test and multivariable logistic regression and stratification test

Result and Discussion: There was no significant correlation between the mode of delivery and the patterns of the first month breastfeeding by including a variable of employment with a value of $\mathrm{OR}(95 \% \mathrm{Cl})=1.6(0.63$ to 4.17$)$ and there was a decrease in the value of $\mathrm{OR}(95 \% \mathrm{Cl})$ from $2.5(1.05$ to 5.94 ) to 1.6 ( 0.63 to 4.17 ); there was also no significant correlation when involving the variable of the incidence of ante partum and post partum with the value of $\mathrm{OR}(95 \% \mathrm{Cl})=1.7(0.45$ to 6.26$)$ and $\mathrm{OR}(95 \% \mathrm{Cl})=2.3(0.96$ to 5.53$)$, respectively.

Conclusion: : There is no difference patterns of breastfeeding mothers first month who gave birth cesarean section compared to normal birth. Caesarean section would affect the pattern of the first month breastfeeding if cesarean section deliveries occurred at housewives and mothers who did not experience the incidence of ante partum.
\end{abstract}

Keywords: pattern of breastfeeding; vaginal deliveries; caesarean section; breast milk

\begin{abstract}
ABSTRAK
Latar Belakang: Pemberian ASI eksklusif harus diberikan hingga usia 6 bulan, tetapi kenyataan membuktikan bahwa pola menyusui menurun. Pola laktasi bulan pertama merupakan masa kritis untuk kelangsungan menyusui berikutnya, sehingga perlu dilakukan upaya untuk menjaga durasi menyusui karena keberhasilan menyusui bulan pertama akan meningkatkan kepercayaan ibu untuk terus menyusui.

Tujuan: Untuk mengetahui perbedaan pola menyusui bulan pertama pada ibu yang melahirkan dengan seksio sesaria dibandingkan dengan persalinan pervaginam di Rumah Sakit Sayang Bayi (Rumah Sakit Bayi Ramah)

Metode: Jenis penelitian observasional komparatif dengan desain kohort prospektif menggunakan pendekatan kuantitatif. Penelitian ini dilakukan di Rumah Sakit Baby Friendly RSUD (Rumah Sakit Umum) Kota Mataram. Total sampel 120 terdiri dari 60 ibu yang melahirkan seksio caesar dan 60 ibu persalinan pervaginam. Variabel independen melahirkan dengan bedah caesar dan persalinan pervaginam, variabel dependen pola menyusui bulan pertama dan variabel eksternal usia, paritas, pekerjaan, kejadian antepartum dan postpartum. Teknik pengambilan sampel menggunakan consecutive sampling. Analisis data yang digunakan adalah univaribel, bivariat menggunakan Chi-square dan uji eksak Fisher dan regresi logistik multivariabel dan uji stratifikasi. Hasil dan Pembahasan: Tidak ada korelasi yang signifikan antara cara persalinan dan pola bulan pertama menyusui dengan memasukkan variabel pekerjaan dengan nilai OR $(95 \% \mathrm{Cl})=1,6(0,63$ hingga 4,17) dan ada penurunan nilai OR $(95 \% \mathrm{Cl})$ dari 2,5 $(1,05$ menjadi 5,94) menjadi 1,6 (0,63 hingga 4,17); juga tidak ada korelasi yang signifikan ketika melibatkan variabel kejadian ante partum dan post partum dengan nilai $\mathrm{OR}(95 \% \mathrm{Cl})=1,7(0,45-$ $6,26)$ dan $\mathrm{OR}(95 \% \mathrm{Cl})=2,3(0,96-5,53)$, masing-masing.

Kesimpulan: Tidak ada perbedaan pola menyusui bulan pertama ibu yang melahirkan seksio sesaria dibandingkan dengan persalinan normal. Seksio sesarea akan mempengaruhi pola pemberian ASI pada bulan pertama jika persalinan seksio sesarea terjadi pada ibu rumah tangga dan ibu yang tidak mengalami kejadian ante partum.
\end{abstract}

Kata kunci: pola menyusui; pengiriman vagina; operasi caesar; ASI 


\section{PENDAHULUAN}

Pemberian ASI yang tidak optimal merupakan masalah kesehatan. Sejak tahun 1999 World Health Organization (WHO) dan United Nations Children (UNICEF) merekomendasikan pemberian ASI eksklusif sampai usia 6 bulan dan menjadikannya sebagai aksi global. Isi deklarasi tersebut menyangkut kerja sama dalam perlindungan, promosi dan dukungan terhadap program pemberian ASI eksklusif dan menghimbau negara-negara di dunia untuk mengambil kebijakan tersebut. ${ }^{1}$

Menurut data, hanya $50,8 \%$ bayi usia 0-1 bulan menerima ASI eksklusif, 31,5\% bayi mendapatkan ASI dan susu lain dan $9,6 \%$ bayi menerima ASI dan makanan pendamping pada usia 0-1 bulan. ${ }^{2}$ Sebuah survei yang dilakukan pada tahun 2000 di Inggris dan Wales, terjadi penurunan prevalensi menyusui bayi dari dari $71 \%$ pada saat lahir sampai $28 \%$ pada bulan keempat. Penurunan prevalensi ini akan menimbulkan kerugiaan ibu dan bayi. ${ }^{3}$ Penurunan dan keterlambatan pemberian ASI biasanya disebabkan oleh persalinan seksio sesaria. Survei tersebut di dukung penelitian di India bayi yang dilahirkan secara seksio secarea mengalami keterlambatan dalam pemberian ASI, bayi lebih sering diberikan minuman prelakteal seperti susu formula dan pemberian kolustrum lebih jarang dari ASI. ${ }^{4}$ Menurut penelitian di Inggris $16 \%$ kematian bayi bisa dicegah jika semua bayi diberi ASI pada hari pertama dan $22 \%$ pada jam pertama, dan risiko kematian neonatal adalah 4 kali lipat lebih tinggi pada bayi yang diberi cairan berbasis susu atau makanan padat selain ASI. ${ }^{5}$

Nusa Tenggara Barat (NTB) merupakan salah satu provinsi dengan tingkat angka kematian neonatal tinggi, yaitu 33/1000 kelahiran hidup dan menempati urutan ke-3 di Provinsi..2 Rumah Sakit Umum Provinsi NTB dan Rumah Sakit Kota Mataram adalah rumah sakit yang sudah menerapkan program sayang ibu dan bayi, tetapi belum maksimal dalam hal pelaksanaan inisiasi menyusu dini (IMD) terutama pada bayi-bayi yang dilahirkan secara seksio sesarea. Tujuan penelitian ini adalah mengetahui perbedaan pola menyusui bulan pertama ibu yang melahirkan seksio sesarea dibandingkan yang melahirkan normal di Rumah Sakit Sayang Bayi.

\section{METODE}

Jenis penelitian ini adalah observasional komparatif dengan menggunakan disain studi cohort. Penelitian ini dilakukan di Rumah Sakit Umum Daerah Kota Mataram pada bulan April dan Mei 2014 dan dilakukan follow up ke rumah masing-masing responden pada minggu I, II, III dan IV. Populasi penelitian ini adalah ibu-ibu yang melahirkan di Rumah Sakit Umum Daerah Kota Mataram berjumlah 130 dengan kriteria Inklusi adalah berdomisili di Kota Mataram, bayi yang lahir sehat, ibu yang bersedia menjadi responden. Kriteria eksklusif adalah bayi pada saat pengumpulan data bayi dalam keadaan sakit/infeksi seperti: diare, ISPA, dll. Teknik pengambilan sampel dengan consecutive sampling. Perkiraan besar sampel yang diperlukan untuk masing-masing kelompok ditentukan menurut besaran sampel dari Lwanga \& lemeshow. ${ }^{6}$ Berjumlah 60 persalinan seksio sesarea dan 60 persalinan normal.

Variabel dalam penelitian ini adalah variabel bebas adalah persalinan seksio secarea dan persalinan normal, variabel terikat adalah pola menyusui bulan pertama dan variabel luar adalah umur, paritas, pekerjaan, kejadian antepartum dan postpartum. Data yang diambil dari penelitian ini bersumber dari data primer dan sekunder RSUD Kota Mataram. Instrumen penelitian kuisioner. Analisis data: univariabel, bivariabel, multivariabel dan menggunakan uji analisis chi square $\left(x^{2}\right)$ dan Fisher's exact test serta uji regresi logistik dengan tingkat kemaknaan $p<0.05$ dan risk ratio (RR) confidence interval 95\%.

\section{HASIL DAN PEMBAHASAN}

1. Lokasi penelitian dan alur pengambilan sampel

Rumah Sakit Umum Daerah Kota Mataram merupakan salah satu Rumah Sakit milik Pemerintah Kota Mataram. Rumah sakit ini mulai operasional dan memberikan pelayanan kepada masyarakat sejak Maret 2010. Penelitian di Rumah Sakit Sayang Bayi RSUD Kota Mataram ini dilakukan pada bulan April dan bulan Mei tahun 2014 dengan jumlah pasien bulan tersebut, yaitu sejumlah 130 persalinan, Adapun uraiannya adalah dari 64 seksio sesarea: 24 riwayat seksio sesarea, 10 kesulitan persalinan (distocia), 2 letak lintang, 2 gawat janin, 13 letak sungsang, 13 kasus-kasus lain dan dari 66 persalinan 
spontan: 60 persalinan normal, 3 persalinan letak lintang, 1 IUFD, 2 persalinan pre term. Yang masuk kriteria eksklusi adalah: 3 letak lintang, 1 IUFD, 2 pre term, 2 bayi sakit, 2 gawat janin, sehingga jumlah responden 120 .
2. Hubungan antara jenis persalinan dengan pola menyusui bulan pertama

Analisis bivariabel untuk mengetahui hubungan variabel bebas: jenis persalinan, variabel terikat: pola menyusui bulan pertama, variabel luar: usia, paritas, pekerjaan, kejadiaan antepartum dan postpartum.

Tabel 1. Hubungan antara jenis persalinan dan variabel luar terhadap pola menyusui bulan pertama

\begin{tabular}{|c|c|c|c|c|c|c|c|}
\hline \multirow{3}{*}{ Variabel } & \multicolumn{4}{|c|}{ Pola menyusui bulan pertama } & \multirow{3}{*}{$\mathbf{p}$} & \multirow{3}{*}{$\mathbf{R R}$} & \multirow{3}{*}{$95 \% \mathrm{Cl}$} \\
\hline & \multicolumn{2}{|c|}{ Tidak ekslusif } & \multicolumn{2}{|c|}{ ASI ekslusif } & & & \\
\hline & $\mathbf{N}$ & $\%$ & $\mathbf{N}$ & $\%$ & & & \\
\hline $\begin{array}{l}\text { Jenis persalinan } \\
\text { Seksio sesarea } \\
\text { Normal }\end{array}$ & $\begin{array}{l}20 \\
10 \\
\end{array}$ & $\begin{array}{l}33 \\
17 \\
\end{array}$ & $\begin{array}{l}40 \\
50 \\
\end{array}$ & $\begin{array}{l}67 \\
83 \\
\end{array}$ & 0,04 & 2,0 & $1,0-3,9$ \\
\hline $\begin{array}{l}\text { Usia } \\
<20 \&>35 \text { tahun } \\
\text { 20-35 Tahun }\end{array}$ & $\begin{array}{c}2 \\
28\end{array}$ & $\begin{array}{l}13 \\
27\end{array}$ & $\begin{array}{l}13 \\
77 \\
\end{array}$ & $\begin{array}{l}87 \\
73 \\
\end{array}$ & $0,22 *$ & 1,8 & $0,9-1,5$ \\
\hline $\begin{array}{l}\text { Paritas } \\
\text { Primipara } \\
\text { Multipara }\end{array}$ & $\begin{array}{c}1 \\
29\end{array}$ & $\begin{array}{l}33 \\
25\end{array}$ & $\begin{array}{c}2 \\
88\end{array}$ & $\begin{array}{l}67 \\
75\end{array}$ & $0,58^{*}$ & 1,3 & $0,3-6,9$ \\
\hline $\begin{array}{l}\text { Pekerjaan } \\
\text { Ibu bekerja } \\
\text { Ibu rumah tangga }\end{array}$ & $\begin{array}{l}19 \\
11\end{array}$ & $\begin{array}{l}43 \\
15\end{array}$ & $\begin{array}{l}25 \\
65\end{array}$ & $\begin{array}{l}57 \\
85\end{array}$ & $<0,001$ & 2,9 & $1,6-5,7$ \\
\hline $\begin{array}{l}\text { Kejadian ante partum } \\
\text { Ada } \\
\text { Tidak ada }\end{array}$ & $\begin{array}{l}20 \\
10 \\
\end{array}$ & $\begin{array}{l}33 \\
17 \\
\end{array}$ & $\begin{array}{l}40 \\
50 \\
\end{array}$ & $\begin{array}{l}67 \\
83 \\
\end{array}$ & 0,04 & 2,0 & $1,0-3,9$ \\
\hline $\begin{array}{l}\text { Kejadian post partum } \\
\text { Ada } \\
\text { Tidak ada }\end{array}$ & $\begin{array}{c}1 \\
29\end{array}$ & $\begin{array}{c}9 \\
27\end{array}$ & $\begin{array}{l}10 \\
80\end{array}$ & $\begin{array}{l}90 \\
73\end{array}$ & $0,18^{*}$ & 0,3 & $0,1-2,3$ \\
\hline
\end{tabular}

*Fisher's exact test.

Keterangan : analisis chi square kecuali yang ada tanda bintang

Catatan :

Kejadian antepartum : riwayat SC, kesulitan persalinan, gawat janin, letak lintang, letak sungsang \& kasus lain. Kejadian postpartum : bendungan ASI \& perdarahan pasca persalinan.

Pada Tabel 1 terlihat bahwa terdapat perbedaan pola menyusui bulan pertama ibu yang melahirkan seksio sesarea dibandingkan dengan ibu yang melahirkan normal $\operatorname{RR}(95 \% \mathrm{Cl})=2,0(1,0-3,9)$ dan $p=0,04$. Hal ini berarti ibu yang melahirkan secara seksio sesarea 2 kali lebih banyak tidak eksklusif dibandingkan yang melahirkan normal.
Variabel luar seperti umur, paritas dan kejadian postpartum tidak mempengaruhi. Status pekerjaan dan kejadian antepartum mempengaruhi RR $(95 \% \mathrm{Cl})$ $=2,9(1,6-5,7)$ dan $p<0,001$ dan $\operatorname{RR}(95 \% \mathrm{Cl})=2,0$ $(1,0-3,9)$ dan $p=0,04$. 
Tabel 2. Perbandingan proporsi kejadian persalinan seksio sesarea dan normal dilihat dari usia paritas, pekerjaan, kejadian antepartum dan postpartum.

\begin{tabular}{|c|c|c|c|c|c|c|c|}
\hline \multirow{3}{*}{ Variabel } & \multicolumn{4}{|c|}{ Jenis persalinan } & \multirow{3}{*}{$p$} & \multirow{3}{*}{ OR } & \multirow{3}{*}{$95 \% \mathrm{Cl}$} \\
\hline & \multicolumn{2}{|c|}{ Seksio sesarea } & \multicolumn{2}{|c|}{ Normal } & & & \\
\hline & $\mathrm{N}$ & $\%$ & $\mathrm{~N}$ & $\%$ & & & \\
\hline $\begin{array}{l}\text { Usia } \\
\text { - }<20 \text { \& >35 tahun } \\
\text { - 20-35 Tahun }\end{array}$ & $\begin{array}{c}9 \\
51\end{array}$ & $\begin{array}{l}15 \\
85\end{array}$ & $\begin{array}{c}6 \\
54\end{array}$ & $\begin{array}{l}10 \\
90\end{array}$ & 0,41 & 1,6 & $0,46-5,81$ \\
\hline $\begin{array}{l}\text { Paritas } \\
\text { - Primipara } \\
\text { - } \text { Multipara }\end{array}$ & $\begin{array}{c}2 \\
58\end{array}$ & $\begin{array}{c}3 \\
97\end{array}$ & $\begin{array}{c}1 \\
59\end{array}$ & $\begin{array}{c}2 \\
98\end{array}$ & $0,5^{*}$ & 2,0 & $0,1-122,0$ \\
\hline $\begin{array}{l}\text { Pekerjaan } \\
\text { - Ibu bekerja } \\
\text { - Ibu rumah tangga }\end{array}$ & $\begin{array}{l}32 \\
28\end{array}$ & $\begin{array}{l}53 \\
47\end{array}$ & $\begin{array}{l}12 \\
48\end{array}$ & $\begin{array}{l}20 \\
80\end{array}$ & $<0,00$ & 4,6 & $1,9-11,3$ \\
\hline $\begin{array}{l}\text { Kejadian ante partum } \\
\text { - Ada } \\
\text { - Tidak ada }\end{array}$ & $\begin{array}{c}53 \\
7 \\
\end{array}$ & $\begin{array}{l}83 \\
12 \\
\end{array}$ & $\begin{array}{c}7 \\
53 \\
\end{array}$ & $\begin{array}{l}12 \\
88\end{array}$ & $<0,001$ & 57,3 & $16,8-204,9$ \\
\hline $\begin{array}{l}\text { Kejadian postpartum } \\
\text { - Ada } \\
\text { - Tidak ada }\end{array}$ & $\begin{array}{c}2 \\
58\end{array}$ & $\begin{array}{c}3 \\
97\end{array}$ & $\begin{array}{c}9 \\
51\end{array}$ & $\begin{array}{l}15 \\
85\end{array}$ & $0,03^{*}$ & 0,2 & $0,0-1,8$ \\
\hline
\end{tabular}

*Fisher's exact test

Keterangan : analisis Chi square kecuali yang ada tanda bintang.

Pada Tabel 5 terlihat bahwa dari $120 \mathrm{ibu}, 32$ (53\%) ibu bekerja melahirkan secara seksio sesaria dengan nilai OR 4,6. Hal ini berarti ibu yang bekerja 4,6 lebih banyak melahirkan secara seksio sesaria dibandingkan dengan ibu yang tidak bekerja, Sedangkan dari 120 ibu, 53 (83\%) ibu yang mengalami kejadian ante partum melahirkan secara seksio sesaria dengan nilai OR 57,3. Hal ini berarti ibu yang mengalami kejadian ante partum 57,3 lebih banyak melahirkan secara seksio sesaria dibandingkan dengan ibu yang tidak mengalami kejadian ante partum.

\section{Analisa regresi logistik}

Berdasarkan analisis bivariabel, variabelvariabel yang bermakna memiliki nilai $p<0.25$ kemudian dianalisis secara multivariabel dengan menggunakan model uji statistik regresi logistik untuk menilai hubungan jenis persalinan dengan pola menyusui bulan pertama. Analisis multivariabel dilakukan dengan 4 model dengan mengikutsertakan variabel luar pekerjaan, kejadian antepartum dan postpartum. Hasil analisis multivariabel dilihat pada Tabel 3. 
Tabel 3. Analisa logistic regresi : Perbedaan pola menyusui bulan pertama ibu yang melahirkan seksio sesarea dibandingkan melahirkan normal dengan mengontrol variabel luar.

\begin{tabular}{|c|c|c|c|c|}
\hline & Model 1 & Model 2 & Model 3 & Model 4 \\
\hline \multirow[t]{2}{*}{ Variabel } & OR & OR & OR & OR \\
\hline & $95 \% \mathrm{Cl}$ & $95 \% \mathrm{Cl}$ & $95 \% \mathrm{Cl}$ & $95 \% \mathrm{Cl}$ \\
\hline $\begin{array}{l}\text { Jenis persalinan } \\
\text { - Seksio sesarea } \\
\text { - Normal }\end{array}$ & $\begin{array}{c}2,5 \\
(1,05-5,94) \\
1\end{array}$ & $\begin{array}{c}1,6 \\
(0,63-4,17) \\
1\end{array}$ & $\begin{array}{c}1,7 \\
(0,45-6,26) \\
1\end{array}$ & $\begin{array}{c}2,3 \\
(0,96-5,53) \\
1\end{array}$ \\
\hline $\begin{array}{l}\text { Pekerjaan } \\
\text { - Ibu bekerja } \\
\text { - Ibu rumah tangga }\end{array}$ & & $\begin{array}{c}3,8 \\
(1,52-9,61) \\
1\end{array}$ & & \\
\hline $\begin{array}{l}\text { Kejadian ante partum } \\
\text { - Ada } \\
\text { - Tidak ada } \\
\text { Kejadian post partum } \\
\text { - Ada } \\
\text { - Tidak ada }\end{array}$ & & & $\begin{array}{c}1,7 \\
(0,45-6,25) \\
1\end{array}$ & $\begin{array}{c}0,4 \\
(0,04-3,09) \\
1 \\
\end{array}$ \\
\hline $\mathrm{N}$ & 120 & 120 & 120 & 120 \\
\hline
\end{tabular}

Keterangan : N: Jumlah sampel, OR: Odds Ratio, 95\%Cl: Convidence interval 95\%

Berdasarkan hasil analisis multivariabel dengan regresi logistik dengan melakukan pemodelan, tidak terdapat hubungan yang bermakna antara jenis persalinan terhadap pola menyusui bulan pertama dengan mengikutsertakan variabel pekerjaan, dengan nilai OR $(95 \% \mathrm{Cl})=1,6(0,63-4,17)$ dan terjadi penurunan nilai dari OR $(95 \% \mathrm{Cl})=2,5(1,05-$ $5,94)$ menjadi OR $(95 \% \mathrm{Cl})=1,6(0,63-4,17)$, begitu pula dengan mengikutsertakan variabel kejadiaan antepartum, tidak terdapat hubungan bermakna jenis persalinan terhadap pola menyusui bulan pertama dengan nilai OR $(95 \% \mathrm{Cl})=1,7(0,45-6,26)$ dan dengan mengikutsertakan variabel kejadiaan post partum tidak terdapat hubungan bermakna dengan nilai OR $(95 \% \mathrm{Cl})=2,3(0,96-5,53)$.

\section{Uji stratifikasi}

Uji stratifikasi adalah cara untuk mengontrol variabel pengganggu dengan mengevaluasi paparan terhadap pola menyusui bulan pertama secara terpisah pada masing-masing variabel pengganggu. Untuk membuktikan seberapa besar hubungan tersebut dilakukan stratifikasi dengan uji Mantel Haesnzel. Berdasarkan analisis bivariabel, variabel luar yang berhubungan dengan jenis persalinan adalah pekerjaan dan kejadian antepartum. Variabel luar dianggap sebagai variabel pengganggu jika nilai bila ada selisih antara nilai RR Crude dengan RR M-H lebih dari $10 \%$. 
Tabel 4. Hasil analisis Stratifikasi jenis persalinan, pola menyusui dan pekerjaan dan kejadian antepartum.

\begin{tabular}{|c|c|c|c|c|c|c|}
\hline \multirow{3}{*}{ Variabel } & \multirow{3}{*}{ Jenis persalinan } & \multicolumn{4}{|c|}{ Pola menyusui } & \multirow{3}{*}{$\begin{array}{c}\mathrm{RR} \\
95 \% \mathrm{Cl}\end{array}$} \\
\hline & & \multicolumn{2}{|c|}{ Tidak ekslusif } & \multicolumn{2}{|c|}{ ASI ekslusif } & \\
\hline & & $\mathrm{N}$ & $\%$ & $\mathrm{~N}$ & $\%$ & \\
\hline $\begin{array}{l}\text { Pekerjaan } \\
\text { - Bekerja } \\
\text { - Tidak Bekerja }\end{array}$ & $\begin{array}{l}\text { - Seksio sesaria } \\
\text { - Normal } \\
\text { - Seksio sesaria } \\
\text { - Normal }\end{array}$ & $\begin{array}{c}14 \\
5 \\
6 \\
5\end{array}$ & $\begin{array}{l}43,6 \\
41,7 \\
21,4 \\
10,4\end{array}$ & $\begin{array}{c}18 \\
7 \\
\\
22 \\
43\end{array}$ & $\begin{array}{l}56,3 \\
58,3 \\
78,6 \\
89,6\end{array}$ & $\begin{array}{c}1,1 \\
0,69-6,13 \\
\\
2,1 \\
0,69-6.13\end{array}$ \\
\hline $\begin{array}{l}\text { Kejadian } \\
\text { antepartum } \\
\text { - Ada } \\
\text { - Tidak ada }\end{array}$ & $\begin{array}{l}\text { - Seksio sesaria } \\
\text { - Normal } \\
\text { - Seksio sesaria } \\
\text { - Normal }\end{array}$ & $\begin{array}{c}18 \\
2 \\
2 \\
8\end{array}$ & $\begin{array}{l}33,9 \\
28,4 \\
28,6 \\
15,1\end{array}$ & $\begin{array}{c}35 \\
5 \\
\\
5 \\
45\end{array}$ & $\begin{array}{l}66,0 \\
71,4 \\
71,4 \\
84,9\end{array}$ & $\begin{array}{c}1,2 \\
(0,35-4,07) \\
1,9 \\
(0,49-7,19)\end{array}$ \\
\hline & & & & & & \\
\hline
\end{tabular}

Pekerjaan : RR Crude: 2, RR MH:1,38, Kejadian ante partum RR Crude: 2 RR MH: 1,43

Pada Tabel 4 terlihat bahwa hasil uji stratifikasi menunjukkan bahwa pekerjaan ibu mempunyai nilai RR Crude $=2$ dan nilai RR $\mathrm{M}-\mathrm{H}=1,38$ dengan nilai perubahan sebesar $=0,31$ (31\%). Hal ini berarti bahwa pekerjaan ibu merupakan variabel pengganggu (counfonding) terhadap hubungan antara jenis persalinan dan pola menyusui bulan pertama.

Variabel kejadian antepartum memiliki perbedaan nilai RR Crude $=2$ dan nilai RR $\mathrm{M}-\mathrm{H}$ $=1,43$. Selisih antara nilai RR Crude dan nilai RR M-H sebesar=0,285 (28,5\%). Hal ini berarti bahwa kejadian antepartum merupakan variabel pengganggu (counfonding) terhadap hubungan antara jenis persalinan dan pola menyusui bulan pertama.

Penelitian ini menunjukkan bahwa setelah dilakukan uji bivariabel bahwa terdapat perbedaan pola menyusui bulan pertama ibu yang melahirkan seksio sesarea dibandingkan melahirkan normal dengan nilai RR 2,0. Artinya, ibu yang melahirkan secara seksio sesarea 2 kali untuk tidak memberikan ASI eksklusif dibandingkan ibu yang melahirkan normal.

Ibu yang melahirkan dengan seksio sesarea cenderung lebih terlambat dalam pemberian asi dalam jangka waktu kurang dari 120 menit atau lebih dari 120 menit, sehingga bayi lebih sering diberi minuman prelakteal. ${ }^{7} \mathrm{Hal}$ ini di perkuat oleh penelitian Leung, Lam, kelahiran secara seksio sesarea adalah faktor resiko yang menyebabkan ibu-ibu tidak menyusui bayinya di awal kelahiran dan menyebabkan ibu-ibu menghentikan menyusui bayinya kurang dari 1 bulan. ${ }^{8}$

Hasil analisis bivariabel menunjukkan bahwa pekerjaan mempengaruhi pola menyusui bulan pertama. Artinya bahwa jumlah ibu yang bekerja dalam pemberian ASI tidak ekslusif lebih banyak dari ibu yang tidak bekerja. Ibu yang bekerja memiliki peluang 2,9 kali untuk tidak memberikan ASI ekslusif dari ibu yang tidak bekerja. Hasil ini sesuai dengan penelitian yang dilakukan oleh, $\mathrm{Chen}, \mathrm{Wu},{ }^{9}$ bahwa ibu-ibu yang bekerja lebih cepat memperkenalkan makanan selain asi seperti susu formula karena akan kembali bekerja, Chuang, Chang menyampaikan bahwa ibu yang cuti melahirkan kurang atau sama dengan 1 bulan lebih cenderung lama menyusui lebih cepat berhenti dari ibu yang cuti lebih dari 1 atau 6 bulan. ${ }^{10}$

Berdasarkan hasil uji bivariabel, ibu yang mengalami kejadian antepartum memiliki 2 kali kemungkinan untuk tidak memberikan ASI ekslusif pada bayinya daripada ibu yang tidak mengalami kejadian antepartum. Kejadian antepartum adalah kejadian selama hamil dan sebelum melahirkan 
yang menyebabkan ibu kesulitan dan keterlambatan dalam pemberian ASI pada bayinya, seperti: riwayat seksio sesarea persalinan sebelumnya, distosia (kesulitan) persalinan, gawat janin, letak sungsang, letak melintang.

Penelitian ini didukung oleh penelitian yang dilakukan oleh Zanardo, Svegliado, ${ }^{11}$ bahwa ibu-ibu yang melahirkan secara seksio sesarea baik karena indikasi darurat maupun elektif akan terjadi penurun pemberian ASI ekslusif dibandingkan dengan ibu yang melahirkan normal. Hal ini disebabkan oleh karena ketidakmampuan ibu di ruang bersalin dan pada periode postpartum untuk menyusui bayinya karena ketidaknyamanan yang dirasakan oleh ibu yang disebabkan oleh nyeri karena adanya luka operasi.

Berdasarkan analisis regresi logistik bahwa tidak terdapat hubungan yang bermakna jenis persalinan terhadap pola menyusui bulan pertama setelah mengikutsertakan variabel pekerjaan dan kejadian antepartum. Pekerjaan dan kejadian antepartum merupakan variabel counfonding.

Hal ini sesuai dengan penelitian yang dilakukan oleh Prior, Santhakumaran melalui studi literatur bahwa persalinan seksio sesarea tidak berpengaruh signifikan terhadap pemberian ASI ekslusif dan jenis persalinan tidak memiliki efek yang jelas terhadap keberlanjutan pemberian ASI eklsusif sampai 6 bulan. ${ }^{12}$ Menurut Edmond, Zandoh, ibu yang berhasil melakukan IMD (inisiasi menyusu dini) mempunyai kemungkinan lebih besar melanjutkan menyusui bayinya dan menyusui akan melindungi bayi dari kematian. ${ }^{5}$ Menurut Dennis, rooming-in dengan bayi setelah melahirkan, mempunyai efek positif bagi ibu untuk menyusui bayinya dan ibu yang melakukan demand feeding (asupan menurut kebutuhan) adalah lebih memungkinkan untuk meneruskan menyusui pada 4-6 minggu dibandingkan dengan ibu yang jarang menyusui bayinya. ${ }^{13}$ Kebijakan di rumah sakit, dan dukungan dari staf dan praktek dokter tentang manajemen menyusui, dan rooming in telah ditunjukkan berdampak positif pada usaha promosi untuk menyusui. ${ }^{14}$ Dengan demikian, permasalahan pemberian ASI di awal kelahiran untuk ibu yang melahirkan secara seksio sesarea bisa diatasi dengan IMD dan romiing-in dengan bayi.

Menurut penelitian Tsai, bahwa bekerja bukan alasan bagi ibu untuk menghentikan pemberian ASI pada bayinya. Ibu-ibu yang bekerja masih bisa memberikan ASI pada bayinya karena di tempat bekerja, ibu bisa menggunakan waktu istirahat untuk memeras ASI nya, mendapat dukungan dari teman kerja dan di tempat kerja tersedia ruangan untuk istirahat dan memeras ASI. ${ }^{15}$

Menurut Belizán, Althabe, kejadian persalinan dengan seksio sesarea lebih banyak ditemukan di negara-negara maju dengan tingkat pendapatan penduduknya tinggi, di daerah perkotaan, di rumah sakit-sakit swasta daripada rumah sakit pemerintahan. ${ }^{16}$ Dari 21 rumah sakit didapatkan data bahwa ibu dengan risiko rendah untuk persalinan seksio sesarea lebih banyak memilih persalinan seksio sesarea daripada persalinan normal, hal ini disebabkan oleh penghasilan yang tinggi dan strata sosial. Dengan demikian, persalinan dengan seksio sesarea bukan hanya disebabkan oleh kejadian antepartum tetapi bisa juga di sebabkan oleh faktorfaktor sosiodemografi.

\section{KESIMPULAN DAN SARAN}

Berdasarkan hasil penelitian, dapat disimpulkan bahwa tidak terdapat perbedaan pola menyusui bulan pertama ibu yang melahirkan seksio sesaria dibandingkan melahirkan normal dan persalinan seksio sesarea akan berpengaruh terhadap pola menyusui bulan pertama jika, persalinan seksio sesarea terjadi pada ibu rumah tangga dan ibu yang tidak mengalami kejadian kejadian ante partum.

Berdasarkan kesimpulan diatas, maka saran yang dapat disampaikan adalah dilakukan promosi kesehatan bagi pasangan suami istri tentang persalinan seksio sesarea dan sebaiknya persalinan sekiso sesarea dilakukan atas indikasi medis, dilakukan edukasi bagi ibu-ibu yang melahirkan secara seksio sesaria tentang teknik menyusui pasca operasi sehingga ibu-ibu tidak mengalami kesulitan pada saat pemberian ASI pasca operasi dan bagi peneliti selanjutnya, perlu melakukan penelitian dengan topik yang sama dengan menggunakan analisis survival.

\section{DAFTAR PUSTAKA}

1. Aarts C, Kylberg E, Hörnell A, Hofvander Y, GebreMedhin M, Greiner T. 2000. How exclusive is exclusive breastfeeding? A comparison of data since birth with current status data. International Journal of epidemiology. 2000;29(6):1041-6. 
2. Badan Pusat Statistik I.C.F International. 2012. Laporan pendahuluan Survei Demografi dan Kesehatan Indonesia 2012. Calverton, Maryland, USA.

3. Wallace LM, Dunn OM, Alder EM, Inch S, Hills RK, Susan M. 2006. A randomised-controlled trial in England of a postnatal midwifery intervention on breast-feeding duration. Midwifery. 2006;22(3):26273.

4. Pai M, M., Sundaram K, Radhakrishnan K, Thomas K, Muliyil JP. 1999. A high rate of Caesarean sections in an affluent section of Chennai: Is it cause for concern? . The National Medical Journal of India. 1999;12(4):156-8.

5. Edmond KM, Zandoh C, Quigley MA, Amenga-Etego S, Owusu-Agyei S, Kirkwood BR.2006. Delayed breastfeeding initiation increases risk of neonatal mortality. Pediatrics. 2006;117(3):e380-e6.

6. Lwanga K, Lemeshow S. 1991. Adequacy of Sample Size in Health Studies. New York: World Health Organization Geneva.

7. Nakao Y, Kazuhiko M, Sumihisa H, Kazuyo 0.2008. Initiation of breastfeeding within 120 minutes after birth is associated with breastfeeding at four months among Japanese women: A self-administered questionnaire survey. BioMed Central. 2008;3(1):17.

8. Leung GM, Lam T-H, Ho L-M. 2002. Breast-Feeding and Its Relation to Smoking and Mode of Delivery. Obstetrics \& Gynecology. 2002;99(5, Part 1):785-94.

9. Chen YC, Wu Y-C, Chie W-C. 2006. Effects of workrelated factors on the breastfeeding behavior of working mothers in a Taiwanese semiconductor manufacturer: a cross-sectional survey. BMC Public Health. 2006;6(1):160.
10. Chuang $\mathrm{C}-\mathrm{H}$, Chang P-J, Chen Y-C, Hsieh W-S, Hurng B-S, Lin S-J, et al.2010. Maternal return to work and breastfeeding: A population-based cohort study. International journal of nursing studies. 2010;47(4):461-74.

11. Zanardo V, Svegliado G, Cavallin F, Giustardi A, Cosmi $E$, Litta P, et al. 2010. Elective cesarean delivery: does it have a negative effect on breastfeeding? Birth. 2010;37(4):275-9.

12. Prior E, Santhakumaran S, Gale C, Philipps LH, Modi N, Hyde MJ. 2012. Breastfeeding after cesarean delivery: a systematic review and meta-analysis of world literature. The American journal of clinical nutrition. 2012:ajcn. 030254.

13. Dennis CL. 2006. Breastfeeding initiation and duration: A 1990-2000 literature review. J Obstet Gynecol Neonatal Nurs. 2006;31(1):12-32.

14. Kovach AC. 2002. A 5-year follow-up study of hospital breastfeeding policies in the Philadelphia area: a comparison with the ten steps. Journal of human lactation. 2002;18(2):144-54.

15. Tsai S-Y. 2014. Employee Perception of BreastfeedingFriendly Support and Benefits of Breastfeeding as a Predictor of Intention to Use Breast-Pumping Breaks After Returning to Work Among Employed Mothers Breastfeeding Medicine. 2014;9(1):16-23.

16. Belizán JM, Althabe F, Barros FC, Alexander $S$, Showalter E, Griffin A, et al. 1999. Rates and implications of caesarean sections in Latin America: ecological study Commentary: all women should have a choice Commentary: increase in caesarean sections may reflect medical control not women's choice Commentary: "health has become secondary to a sexually attractive body". Bmj. 1999;319(7222):1397-402. 